\title{
Alix, a novel mouse protein undergoing calcium-dependent interaction with the apoptosis-linked-gene 2 (ALG-2) protein
}

\author{
Marc Missotten ${ }^{1}$, Anthony Nichols ${ }^{1}$, Klaus Rieger ${ }^{2}$ and \\ Rémy Sadoul ${ }^{1,3}$ \\ 1 Serono Pharmaceutical Research Institute, 14 Chemin des Aulx, 1228 Plan les \\ Ouates, Geneva, Switzerland \\ 2 Centre de Génétique Moléculaire du Centre National de la Recherche \\ Scientifique, Gif-sur-Yvette, France \\ ${ }^{3}$ corresponding author: fax: +41227946965 \\ e.mail:remy.sadoul.ch_gva03@serono.com
}

Received 13.7.98; revised 10.9.98; accepted 17.9.98

Edited by S.J.Martin

\begin{abstract}
ALG-2 is a EF hand calcium binding protein with sequence homologies to calmodulin. Vito et al have shown that ALG-2 expression is required for apoptosis following a number of death stimuli, ${ }^{1}$ although nothing is known about the effectors which underlie ALG-2 function. Here we have used ALG-2 as bait in a yeast two hybrid screen of a mouse brain cDNA library. We found that ALG-2 binds to itself and to a novel protein that we call $\underline{A L G-2}$ interacting protein $\underline{X}$, Alix. Using coimmunoprecipitation experiments, we confirmed ALG-2/ ALG-2 binding and demonstrated that this interaction is calcium independent. ALG-2/Alix interaction was also validated by co-immunoprecipitation, but in this case, the binding was found to be strictly calcium dependent. Alix seems highly conserved throughout evolution since it shows significant homologies to a putative $C$. elegans protein (YNK1) and to proteins of $A$. nidulans (PaIA) and $S$. cerevisiae (BR01). Alix is a potential regulator or downstream effector of ALG-2 action.
\end{abstract}

Keywords: cell death; calcium; ALG-2; Alix; Bro1; PalA

Abbreviations: ALG-2; apoptosis-linked-gene-2; Alix: Alg-2 interacting protein $\mathrm{X}$

\section{Introduction}

The cell death program underlying apoptosis is a highly regulated process, controlled by members of the Bcl-2- and caspase-gene families with cell fate resulting from a balance of death-inducing and survival-promoting signals. Cytosolic calcium is one such signal which, depending on the cellular context, is able to promote either cell death or survival. Hence, in some cases increased $\mathrm{Ca}^{2+}$ concentration, such as following thapsigargin- or $\mathrm{Ca}^{2+}$ ionophore-treatment, is capable of inducing apoptosis. Furthermore, sustained calcium release following TCR stimulation in thymocytes or
NMDA receptor activation in neurons, is essential for the death process. In contrast, elevation in intracellular $\mathrm{Ca}^{2+}$ can also rescue cells from certain death stimuli. For example chronic depolarisation which induces $\mathrm{Ca}^{2+}$ entry in neurons can protect these cells from neurotrophic factor deprivation and hematopoietic cells are protected from IL-3 deprivation by $\mathrm{Ca}^{2+}$ ionophores. ${ }^{2}$ The molecular mechanisms which differentially drive an elevation in intracellular $\mathrm{Ca}^{2+}$ into cell death or survival are poorly understood.

Recently Vito et al have characterised the Apoptosis Linked Gene-2 (ALG-2) $)^{1,3}$ which codes for a $\mathrm{Ca}^{\frac{2+}{2+}}$ binding protein. Inhibition of ALG-2 expression protected lymphoid cells against TCR-induced cell death although it did not appear to interfere with other aspects of TCR signalling as neither IL-2 production nor Fas induction were impaired in cells lacking ALG-2. These cells were also protected against Fas-, ceramide- (a downstream effector of Fas) and dexamethasone-induced death. The lack of ALG-2 expression blocked cell death without impairing caspase activation suggesting that ALG-2 exerts its function at a distal step common to several apoptotic pathways. ${ }^{4}$ ALG-2 encodes a protein of 191 amino acids containing five potential calcium binding sites with strong homology to calmodulin 'EF hands' motifs. ${ }^{5}$ It also shows high level of homology to sorcin a protein tightly associated with the ryanodine receptor, ${ }^{6}$ and to grancalcin a cytosolic protein identified in neutrophils and monocytes which displays $\mathrm{Ca}^{2+}$ dependent translocation to membranes. ${ }^{7}$

Because of its homology with calmodulin, which after binding to calcium, interacts with and modifies the properties of a number of proteins including enzymes, ${ }^{8}$ we thought that ALG-2 may interact and activate downstream effectors of the apoptotic program in a calcium regulated way. As a first step to establish the nature of such effectors, we used the yeast two hybrid system to characterise ALG-2 interacting proteins. An adult mouse brain library was screened and several clones identified. One of these clones encoded part of ALG-2. Another clone encoded a novel mouse protein that we call Alix (ALG-2 interacting protein $\mathrm{X}$ ). Alix shows strong homologies to YNK-1 an open reading frame in $C$. elegans and to proteins in $S$. cereviciae and $A$. nidulans. We found that the interaction between ALG-2 and Alix is strictly dependent on calcium, suggesting that Alix could participate in a regulatory $\mathrm{Ca}^{2+}$ dependent pathway controlled by the ALG2 protein.

\section{Results and Discussion}

\section{Two-hybrid screen for ALG-2 interacting proteins}

We set out to identify and characterise ALG-2 interacting proteins using the yeast two-hybrid system. A cDNA encoding 
the full-length ALG-2 was fused to the DNA binding domain of the GAL4 transcription factor and used to screen a mouse brain cDNA library fused to the GAL4 activation domain. Fourteen positive clones were obtained from approximately 1 million transformants. Eleven of these cDNAs were identical and contained inserts of $700 \mathrm{bp}$. These clones are currently being characterised and will not be described herein. Among the three remaining cDNA clones, one was a partial $900 \mathrm{bp}$ insert encoding the last 92 amino acids of the ALG-2 Cterminal region. This suggested that ALG-2 interacts with itself and that the $\mathrm{C}$ terminal half of the protein is sufficient for binding. The two remaining clones analyzed were identical cDNAs of $1700 \mathrm{bp}$, containing an unknown open reading frame encoding 401 amino acids followed by a stop codon and approximately $500 \mathrm{bp}$ of untranslated sequence. We next used this cDNA to screen a $\lambda$ gt10 mouse cDNA library to obtain a full-length clone. This allowed us to isolate a $1710 \mathrm{bp}$ fragment which although containing a large overlap (500 bp) with the $5^{\prime}$ end of the two hybrid screen product did not include a translation initiation codon. This partial cDNA was used to scan EST databases. A mouse EST clone was found that contained sequences overlapping with the $1710 \mathrm{bp}$ cDNA and a putative ATG initiator codon, fitting a Kozak consensus sequence $^{9}$ (accession number: GenBank W97887). The $5^{\prime}$ end of the complete cDNA was cloned by RT-PCR, using mouse brain RNA as template. The three partial cDNA fragments were then ligated using overlapping sequences and appropriate restriction enzymes to generate a full length cDNA. The protein encoded by this cDNA was named Alix, for ALG-2 interacting protein $\underline{X}$.

Subsequent sequence analysis of the complete EST clone revealed an open reading-frame of 222 amino acids. The nucleotide sequences encoding the first 158 amino acids as well as the last 64 amino acids of the EST clone were identical to the $5^{\prime}$ end and the $3^{\prime}$ end of Alix cDNA, respectively. Since the large central part of the full-length Alix cDNA was missing, this EST clone might represent an alternative spliced variant of Alix. We called this second clone Alix SF (Alix short form).

\section{Mouse Alix shows strong homologies with proteins in C. elegans, $A$. nidullans, $S$. cerevisiae and with mouse Rhophilin}

The deduced amino acid sequence from the mouse Alix cDNA is shown in Figure 1a. It encodes a protein of 869 amino acids with a predicted molecular weight of $96 \mathrm{kD}$. The last 140 amino acids of the protein are particularly rich in proline and tyrosine and contain several Src homology domain 3 (SH3) binding motives (PXXP, boxed in grey) and WW binding domains (XPPXY, aa 723-727 and 834-838). Since ALG-2 does not contain sequences reminiscent of neither $\mathrm{SH} 3$ nor WW domains, ${ }^{10}$ this suggests that the WW- and SH3-binding domains of Alix are involved in interactions with proteins other than ALG-2. An additional feature of the protein is the presence of a consensus tyrosine phosphorylation site (black box, consensus: Prosite: PDOC00007: [RK]-X(2,3)[DE]-X(2,3)-Y).

Comparison of the predicted amino acid sequence with sequences in Genbank showed that Alix is homologous
(40.4\% identity) to YNK-1, the putative $98 \mathrm{kD}$ product of an open reading frame in $C$. elegans (Genbank accession number: Z29561). In addition, Alix shows significant homologies with YOR 275c (28.6\%, identity), a 661 amino acids-open reading frame from $S$. cerevisiae (accession number Q12033), and to known proteins in $A$. nidulans (PalA, 798 aa, 27.4\% identity) and in S. cerevisiae (BRO1, 844 aa, $24.5 \%$ identity) ${ }^{11,12}$ (Figure 1b). Noteworthy is the perfect conservation of the putative Tyr phosphorylation site between all proteins. Despite these homologies, conservation between the different proteins is lower within their $\mathrm{COOH}$ terminal region. In particular, the open reading frame YOR 275c encodes a protein lacking the proline rich region found in Alix, YNK-1, PalA and BRO1. In addition, the $\mathrm{N}$ terminal part of Alix also shows strong homologies with the GTP-Rho binding protein Rhophilin ${ }^{13}$ within its $N$ terminal region (34\% identity within aa 121-385 of Rhophilin).

\section{Tissue distribution of Alix}

We next investigated Alix and ALG-2 tissue distribution by Northern blot analysis of different adult mouse tissues. As shown in Figure 2 Alix and ALG-2 are widely expressed in all tissues analyzed. As previously described, a $1.3 \mathrm{~Kb}$ band was detected for ALG-2. ${ }^{1}$ Using Alix SF CDNA as a probe, we could detect two different transcripts of approximately $3.5 \mathrm{~Kb}$ and $6.5 \mathrm{~Kb}$. A similar pattern was observed when we used a probe covering the central part of Alix cDNA (not shown). Since this region is missing in Alix SF cDNA, this suggests that none of the two transcripts correspond to the putative spliced variant of Alix cDNA.

\section{Alix/ALG-2 and ALG-2/ALG-2 interactions are $\mathrm{Ca}^{2+}$ - dependent and -independent, respectively}

In order to confirm the Alix/ALG-2 and ALG-2/ALG-2 interactions detected in the yeast two hybrid system, we next performed co-immunoprecipitation experiments of overexpressed proteins in human embryonic kidney 293 cells (HEK 293 cells). Cells were transiently co-transfected with expression vectors coding for Myc-tagged Alix, Flag- or Myctagged ALG-2 or Flag-tagged sorcin, as indicated. Sorcin, which is the closest homologue of ALG-2 within the calmodulin family (39\% identity) was used as a control. Twenty-four hours later, cells were lysed and immunoprecipitated using an anti-Myc monoclonal antibody. Co-precipitating proteins were revealed by immunoblotting using an antiFlag monoclonal antibody. The effect of calcium on protein interactions was tested by performing lysis and immunoprecipitations in presence or absence of $\mathrm{Ca}^{2+}$.

Figure 3 shows that ALG-2 co-precipitated strongly with Alix in a buffer containing $5 \mathrm{mM} \mathrm{CaCl}_{2}$. This interaction was strictly $\mathrm{Ca}^{2+}$ dependent since it did not occur when $\mathrm{CaCl}_{2}$ was replaced by $\mathrm{MgCl}_{2}$. Sorcin did not co-precipitate with Alix in presence or absence of $\mathrm{Ca}^{2+}$ demonstrating the specificity of the Alix/ALG-2 interaction.

A truncated Alix possessing 401 amino acids of the Cterminal region and corresponding to the cDNA isolated 
using the yeast two hybrid system (Alix CT) could also precipitate ALG-2. In contrast, Alix lacking the C-terminal half (Alix NT) or most of the central part of the protein (Alix
SF) did not interact with ALG-2 (Figure 4). These results indicate that the region between aa 468 and 806 of Alix contains the domain of interaction with ALG-2.

a

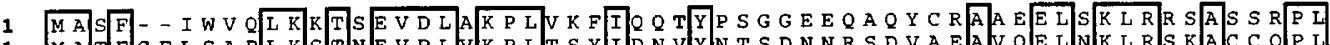

1 MA Th G F L S A P P

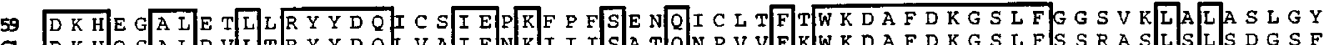

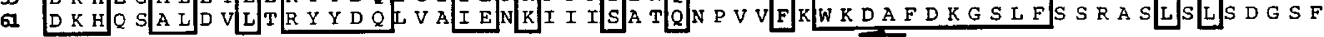

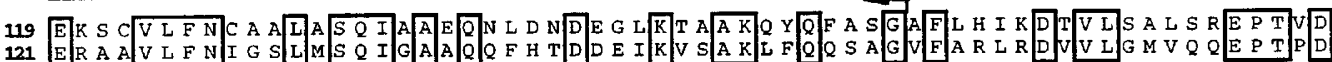

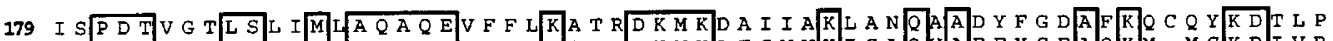

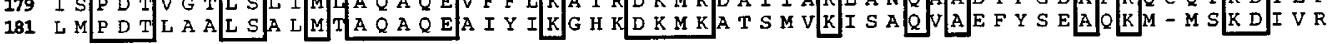

$239---$ -

2al

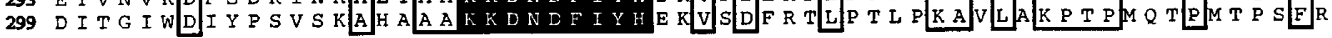

353 RER VPVIVDOSLAVFSORKADLVNRSIAO MREATTDA NGVLASLNLPAAIEDVG D

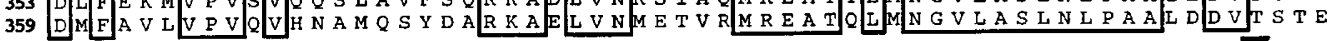

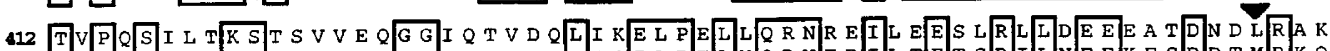

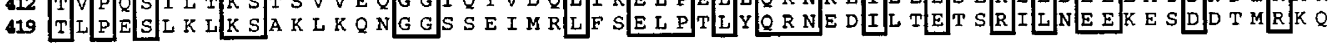

Alix

$\operatorname{lng}$

Alix

nk-1

Alix

Alix

nkx-1

Alix

Alix

nXx-1

Alix

nXx-1

Alix

Alix

nexk-1

Nix

Alix

nk-1

Alix

2XX-1

Alix

Alix

b

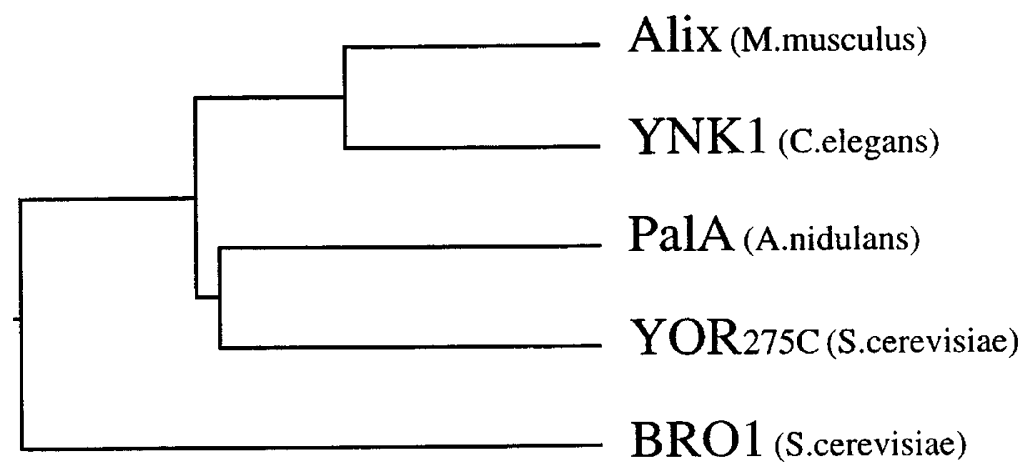

Figure 1 Primary amino acid sequence of mouse Alix and comparison with $C$. elegans YNK-1. (a) Deduced amino acid sequence from the mouse Alix full-length cDNA. Amino acids identical in both mouse Alix and the $C$. elegans YNK-1 are boxed. The black box represents a tyrosine phosphorylation consensus site. The two horizontal arrows indicate the amino acids juxtaposed in the Alix short form sequenced from the mouse EST clone (accession number W97887). The SH3 binding motifs are boxed in grey. The first residue of the clone isolated from the yeast two hybrid screen is indicated by a filled vertical arrow. (b) Sequence relatedness of Alix and its homologues; lengths of the branches represent the average identities between the different members. The sequence alignment and dendogram were computed with Laser Gene-Megalin software (DNAstar, Madison, WI, USA) 

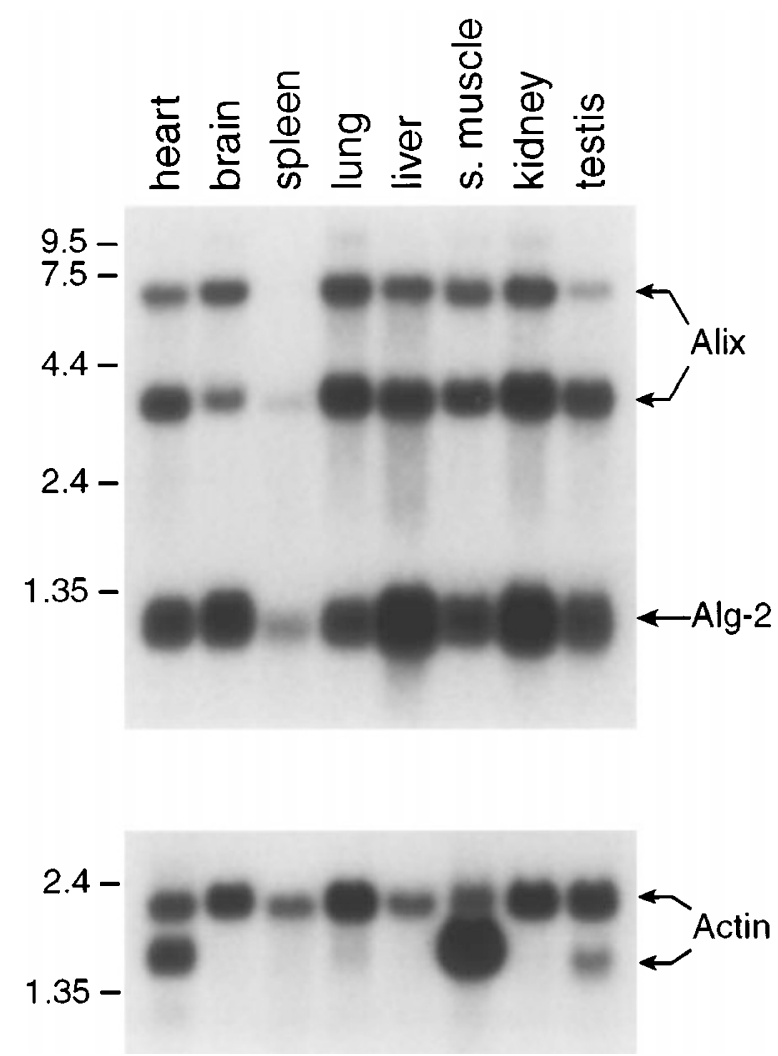

Figure 2 Alix mRNA distribution. Poly $(\mathrm{A})^{+} \mathrm{RNA}(2 \mu \mathrm{g})$ from different adult mouse tissues (Clontech) was probed with ${ }^{32} \mathrm{P}$-labelled Alix and ALG-2 under high stringency conditions. Human $\beta$-actin was used as an internal standard control

Because Alix sequence contains no obvious $\mathrm{Ca}^{2+}$ binding motif, our results suggest that the interaction between Alix and ALG-2 occurs following the binding of $\mathrm{Ca}^{2+}$ to ALG-2. As with other EF hand protein, ALG-2 may act as a sensor of intracellular $\mathrm{Ca}^{2+}$, undergoing a conformational change upon $\mathrm{Ca}^{2+}$ binding to allow its interaction with Alix.

In contrast to the $\mathrm{Ca}^{2+}$ dependent interaction between Alix and ALG-2, ALG-2 precipitated with itself in presence or absence of $\mathrm{Ca}^{2+}$ (Figure 3). Within the calmodulin family, ALG-2 is a member of a subfamily including calpain, grancalcin, sorcin and an open reading frame in $S$. cerevisiae. All of these proteins contain $5 \mathrm{EF}$-hands $(\mathrm{EF}-1-5)$ and have been shown to bind $\mathrm{Ca}^{2+} \cdot{ }^{2}$ Grancalcin and sorcin exist as homodimers. The $\mathrm{Ca}^{2+}$ binding domain of the small subunit of calpain has recently been shown to form homodimers in absence of the catalytic subunit. In this latter case, X-ray crystallography has revealed that one EF-5 pairs up with another EF-5 in a $\mathrm{Ca}^{2+}$ independent fashion. ${ }^{14,15}$ ). Our results indicate that the last 92 amino acids of ALG-2 which contain EF-5, EF-4 and part of EF-3 are sufficient to interact with ALG-2. This suggests that ALG-2 may also form dimers and raises the
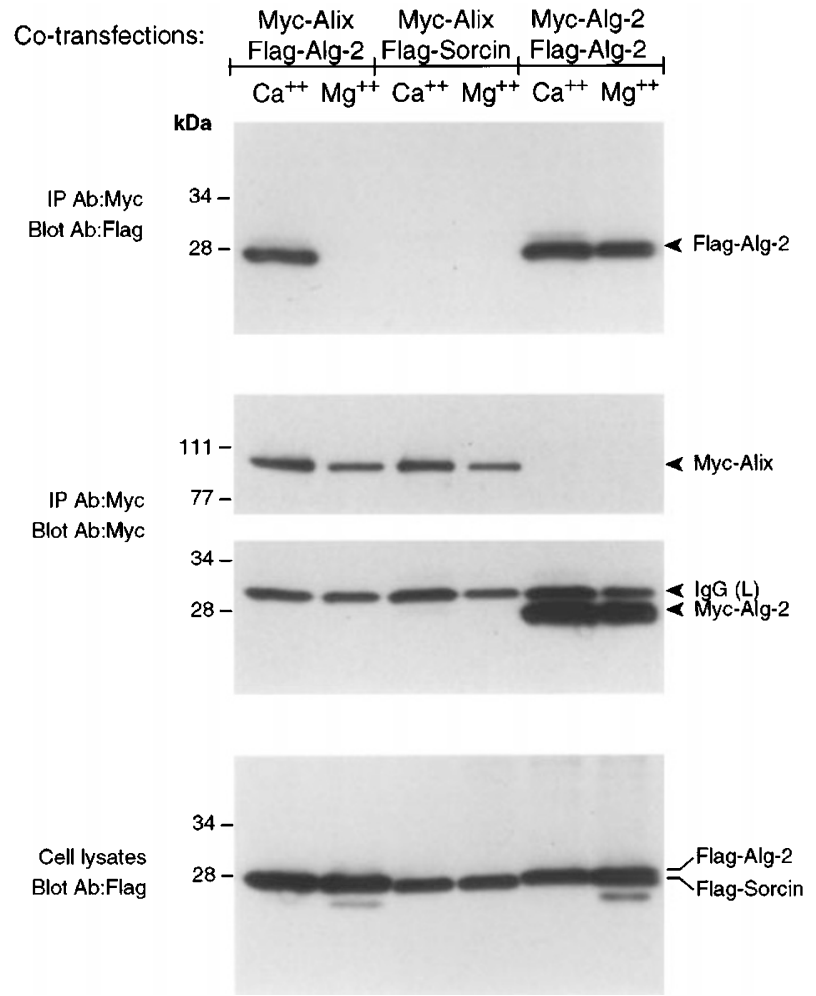

Figure 3 Differential effects of $\mathrm{Ca}^{2+}$ on ALG-2/ALG-2 and Alix/ALG-2 interactions. HEK 293 cells wer ${ }^{11}$ e transiently co-transfected with expression vectors encoding Myc tagged or Flag tagged-Alix, -ALG-2 and -sorcin, as indicated. Cells were lysed in buffer containing either $5 \mathrm{mM} \mathrm{CaCl} \mathrm{Cr}_{2}$ or $5 \mathrm{mM}$ $\mathrm{MgCl}_{2}$ together with $1 \mathrm{mM}$ EGTA. Immunoprecipitations of Alix and ALG-2 were performed using an anti-Myc monoclonal antibody. Co-immunoprecipitated proteins were revealed using an anti-Flag monoclonal antibody (upper panel). Immunoprecipitated Alix and ALG-2 as detected using anti-Myc antibody are shown in the middle panels. The lower panel shows ALG-2 and sorcin proteins in the transfected cell lysates, as revealed by the anti-Flag antibody

question of the role of EF-5 in this $\mathrm{Ca}^{2+}$ independent homophilic interaction.

The function of Alix is today unknown. It is noteworthy that PalA is part of a signal transduction pathway mediating $\mathrm{pH}$ regulation of gene expression and thereby participating in ambient $\mathrm{pH}$ regulation in $A$. nidulans. ${ }^{11}$ Nickas and Yaffe have shown that BRO1 interacts with components of the Pkc1p-mitogen-activated protein kinase pathway in yeast. ${ }^{12}$ One may therefore hypothesise that members of the Alix family are involved in signal transduction regulated by $\mathrm{Ca}^{2+}$ and $\mathrm{Ca}^{2+}$ binding proteins such as ALG-2. The presence of proline rich sequences within the $\mathrm{C}$-terminal region of these proteins may indicate that they bind to cytoskeletal and signal transduction proteins containing $\mathrm{SH} 3$ and $\mathrm{WW}$ domains. Using Alix as bait in a yeast two hybrid system may help to identify additional interacting proteins and thereby give an insight into the protein's function in the cell death program. These studies are currently underway in our laboratory. 


\section{Materials and Methods}

\section{Biological reagents and cell culture}

The anti-Flag BioM2 monoclonal antibody was purchased from Eastman Kodak Company (New Haven, CT, USA). Anti-Biotin-POD monoclonal antibody was provided by Boehringer Mannheim Biochemica (Germany). Anti-Myc monoclonal as well as anti-Myc

a
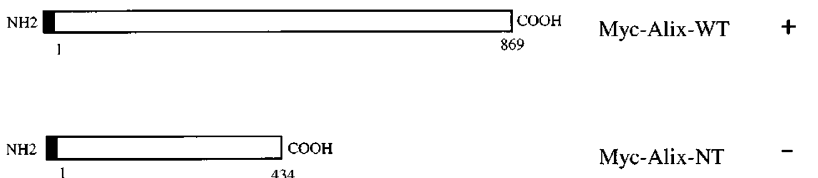

Myc-Alix-NT

434

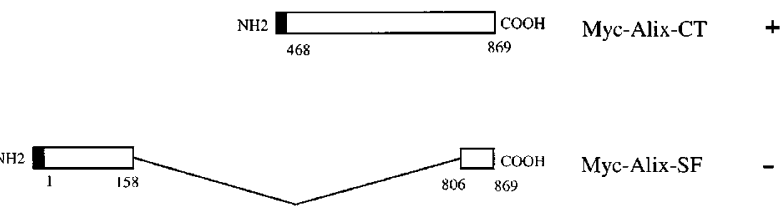

Myc-Alix-CT

b
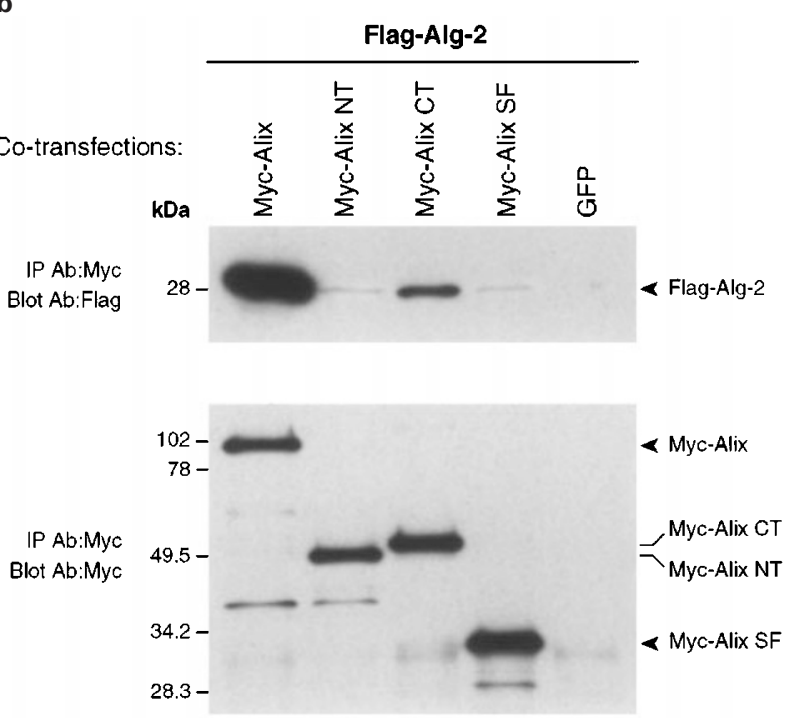

Cell lysates Blot Ab:Flag

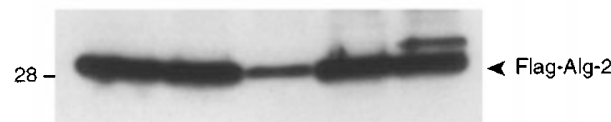

Figure 4 The $\mathrm{COOH}$ half part of Alix is necessary for its binding with ALG2. (a) Schematic representation of Alix deletion mutants used in (b). The black boxes at the $\mathrm{N}$ terminus of the proteins represent the Myc tag. Numbers correspond to amino acid positions. (+) and $(-)$ indicate the ability of the protein to interact with ALG-2. (b) Co-immunoprecipitations of Alix deletion mutants with ALG-2. HEK 293 cells were transiently cotransfected with Myc tagged-Alix WT, -Alix NT, -Alix CT, -Alix SF and Flag tagged-ALG-2. The green fluorescent protein (GFP) was used as a control. Cells were lysed in presence of $5 \mathrm{mM} \mathrm{CaCl}$. Alix proteins were immunoprecipitated with the anti-Myc monoclonal antibody and immunodetected with an anti-Myc polyclonal antibody (middle panel). Coimmunoprecipitation of ALG-2 (upper panel) and cell lysates (lower panel) were revealed by immunoblotting with the anti-Flag monoclonal antibody polyclonal antibodies were from Santa Cruz Biotechnology (Santa Cruz, CA, USA). Human embryonic kidney 293 cells and Hela cells were maintained in DMEM/F12 medium (Gibco BRL) containing 10\% Foetal Calf Serum, using standard cell culture conditions.

\section{Yeast two hybrid cloning}

ALG-2 cDNA was cloned into the yeast expression vector pGBT9 containing the GAL-4 DNA binding domain (Clontech) to be used as bait in a two hybrid screen of an adult mouse brain library cDNA (Clontech). The screen was performed in S. cerevisiae Y190 according to the matchmaker two hybrid system protocol (Clontech). Yeast DNA from positive clones was recovered and transformed into DH5- $\alpha$ cells (Clontech). cDNAs were sequenced with a Perkin Elmer/ $\mathrm{ABI} 373 \mathrm{XL}$ sequencer.

\section{cDNA cloning}

ALG-2 cDNA was amplified by RT - PCR using mouse brain RNA as template. The primers were designed according to the sequence published, ${ }^{1}$ (primer 5'-GCCATGGGGATCCGTGTGCATCAGCCCATGGCTG, primer 3'-AGGCCTGGTTATACAATGCTG). The PCR product was subcloned into the yeast expression vector pGBT9 and into the mammalian expression vector $\mathrm{pCl}$ (Promega) containing either Myc or Flag epitope tag. Sorcin cDNA was amplified by RT-PCR using human brain cortex RNA. The primers were designed using the sequence published $^{16}$ primer 5'-AGGATCCATAGCATGGCGTACCCGGGGCAT, primer 3'-AGGAGAGCTCCAGTTGGAATGTTGATTACA). The PCR product was subcloned into $\mathrm{pCl}$ with a Flag tag.

A full-length CDNA encoding mouse Alix was cloned into the Bluescript $\mathrm{KS}^{+}$vector in three steps; (1), a 1700 bp EcoRI fragment subcloned in the pGAD10 vector (Clontech) was obtained by the two hybrid screen; (2); a 1707 bp insert, containing approximately $500 \mathrm{bp}$ of overlapping sequences at the $5^{\prime}$ end of the two hybrid product, was obtained by screening a $\lambda$ gt10 mouse cDNA library (Clontech) and subcloned into the EcoRI site of Bluescript $\mathrm{KS}^{+}$vector; (3); a $410 \mathrm{bp}$ fragment, containing $209 \mathrm{bp}$ of overlapping sequences with the former insert, was amplified by RT - PCR using mouse brain RNA as template and subcloned into the Smal site of Bluescript $\mathrm{KS}^{+}$. The primers were designed using an EST sequence (accession number: W97887) (primer 5'-TCACCATGGCGTCGTTCATC, primer 3'TCTGCTGCAATCTGGCTAGC). The three fragments were ligated together into Bluescript $\mathrm{KS}^{+}$using appropriate restriction enzymes.

Alix-NT was cloned by excising a Sall fragment of Alix full-length and corresponds to aa $1-434$. Alix-CT (aa 468-869) is the product of the two hybrid screen. Alix-SF (aa 1-158 and aa 806-869) corresponds to the EST sequence described above. The different Alix cDNAs were all subcloned into $\mathrm{pCl}-\mathrm{Myc}$ vector.

\section{Northern blot hybridisation}

Northern blot analysis of mouse tissues (Clontech) was performed according to the instructions of the manufacturer. The ALG-2 probe was the full-length cDNA. For Alix, we used either the Alix-SF cDNA or a $500 \mathrm{bp}$ fragment corresponding to nucleotides 1403 to 1903.

\section{Transfections, coimmunoprecipitations and Western blot analysis}

HEK 293 cells at $50 \%$ confluence were co-transfected with a total of $10 \mu \mathrm{g}$ of DNA in $10 \mathrm{~mm}$ petri dishes by calcium phosphate 
precipitation. After $24 \mathrm{~h}$, cells were lysed in $500 \mu \mathrm{l}$ of either lysis buffer A (142.5 mM KCl, $5 \mathrm{mM} \mathrm{CaCl}_{2}, 10 \mathrm{mM}$ HEPES, 0.2\% NP40, pH 7.4) or lysis buffer $B(142.5 \mathrm{mM} \mathrm{KCl}, 5 \mathrm{mM} \mathrm{MgCl}, 1 \mathrm{mM}$ EGTA, $10 \mathrm{mM}$ HEPES, $0.2 \%$ NP40, pH 7.4). Protease inhibitors were added according to the manufacturer protocol (complete, Mini EDTA-free, Boehringer Mannheim, Germany). Cellular debris were removed by centrifugation at $10,000 \times g$ for $10 \mathrm{~min}$, and $300 \mu \mathrm{l}$ of the supernatants were pre-incubated $4 \mathrm{~h}$ at $4^{\circ} \mathrm{C}$ with $30 \mu \mathrm{l}$ of protein G-agarose (Boehringer Mannheim, Germany). After discarding the beads, the lysates were incubated for $16 \mathrm{~h}$ at $4^{\circ} \mathrm{C}$ with $1 \mu \mathrm{g}$ of anti-Myc monoclonal antibody. Thirty $\mu$ l of protein $\mathrm{G}$ agarose was then added to the antibody-containing-supernatants and incubated for a further hour at $4^{\circ} \mathrm{C}$. The beads were then washed extensively with buffer $\mathrm{A}$ or B. Bound proteins were run on a $4-20 \%$ SDS-polyacrylamide gel (Novex, CA, USA) and transferred on nitro-cellulose membranes (Novex). Immunoblot analysis was performed using anti-Myc monoclonal or polyclonal antibody, or with anti-Flag Bio-M2 monoclonal antibody.

\section{Note added in proof}

Since the submission of this article, a novel putative protein tyrosine phosphatase (PTP-TD14; Genbank acc: AF077000) has been cloned which shows in its $\mathrm{NH} 2$ terminal part high homologies with Alix $(25 \%$ identity on $650 \mathrm{aa}$ ), YNK-1, PalA and Bro1 (Cao et al. (1998) J. Biol. Chem. 273: 21077-2183). Therefore this putative phosphatase which suppresses Ha-ras mediated transformation may be the first member of the Alix family with an enzymatic activity.

\section{Acknowledgements}

We thank all our friends and colleagues for support, in particular $\mathrm{K}$. Sadoul, Y. Chvatchko, J.C. Martinou, S. Arkinstall, for helpful discussions and comments on the manuscript, François Rassendren for help with the sequence analysis, C. Hebert for art work. The nucleotide sequences reported in this paper have been submitted to EMBL Data Bank with accession numbers: AJ005073 (Alix); AJ005074 (Alix SF).
2. McConkey DJ and Orrenius S (1997) The role of Calcium in the regulation of apoptosis. BBRC 239: 357-366

3. D'Adamio L, Lacana' $E$ and Vito $P$ (1997) Functional cloning of genes involved in T-cell receptor-induced programmed cell death. Sem. Immuno. 9: 17-23

4. Lacana E, Ganjei JK, Nito P and D'Adamio L (1997) Dissociation of apoptosis and activation of IL-1b-converting enzyme/ced-3 proteases by ALG-2 and the truncated Alzheimer's gene ALG-3. J. Immuno. 158: 5129-5135

5. Maki M, Narayana VL and Hitomi K (1998) A growing family of the Ca2+-binding proteins with five EF-Hand motifs. Biochem. J. 328: 718-720

6. Lokuta AJ, Meyers MB, Sander PR, Fishman Gl and Valdiva HH (1997) Modulation of cardiac ryanodine receptors by sorcin. J. Biol. Chem. 272: 253325338

7. Boyhan A, Casimir CM, French JK, Teahan CG and Segal AW (1992) Molecular cloning and characterization of grancalcin, a novel EF-hand calcium-binding protein abundant in neutrophils and monocyrtes. J. Biol. Chem. 267:2928-2933

8. Ikura M (1996) Calcium Binding and conformational responses in EF-hand proteins. TIBS 1: $14-17$

9. Kozak M (1986) Point mutations define a sequence flanking the AUG initiator codon that modulates translation by eukaryotic ribosomes. Cell 44: 283-292

10. Sudol M (1996) The WW module competes with the SH3 domain? TIBS 5: 161 163

11. Negrete-Urtasun S, Denison S and Arts H (1997) Characterization of the $\mathrm{pH}$ signal transduction pathway gene palA of Aspergillus nidulans and identification of possible homologs. Journal of Bacteriology 179: 1832-1835

12. Nickas ME and Yaffe MP (1996) BRO1, a novel gene that interacts with components of the Pkc1p-mitogen-activated protein kinase pathway in Saccharomyces cerevisiase. Mol. Cell. Biol. 16: 2585-2593

13. Watanabe G, Saito Y, Madaule P, Ishizaki T, Fujisawa K, Morii N, Mukai H, Ono Y, Kakizuka A and Narumiya S (1996) Protein kinase N (PKN) and PKN-related protein rhophilin as targets of small GTPase Rho. Science 271: 645-648

14. Blanchard H, Grochulski P, Li Y, Arthur JSC, Davies PL, Elce JS and Cygler M (1997) Structure of a calpain Ca2+-binding domain reveals a novel EF-hand and Ca2+-induced conformation changes. Nat. Struct. Biol. 4: 532-538

15. Lin G, Chattopadhay D, Maki M, Wang KKW, Carson M, Jin L, Yuen P, Takano E, Hatanaka M, DeLucas LJ and Narayana SVL (1997) Crystal structure of calcium bound domain VI of calpain at $1.9 \mathrm{~A}$ resolution and its role in enzyme assembly, regulatioan, and inhibitor binding. Nat. Struct. Biol. 4: 539-547

16. Van der Bliek AM, Meyers MB, Biedler JL, Hes E and Borst P (1986) A 22-kd protein (sorcin/V19) encoded by an amplified gene in multidrug-resistantcells, is homologous to the calcium-binding light chain of calpain. EMBO J. 5: $3201-$ 3208

\section{References}

1. Vito $P$, Lacana $E$ and D'Adamio $L$ (1996) Interfering with apoptosis: $\mathrm{Ca}(2+)$ binding protein ALG-2 and Alzheimer's disease gene ALG-3. Science 271:521 525 